Z. klin. Chem. u. klin. Biochem.

9. Jg., S. $320-323$, Juli 1971

\title{
Freies Thyroxin im Serum
}

\section{(Äquilibriumdialyse mit nativem und verdünntem Serum)}

\author{
Von J. Herrmann und H. L. KrüsKemper
}

Abt. II (Klinische Endokerinologie), Dept. Innere Medizin, Medizinische Hocbscbule Hannover.

(Eingegangen am 8. Februar 1971)

Es werden 2 Modifikationen der STERLING-BrenNer-Methode, die die Bestimmung des freien Thyroxins aus nativem und verdünntem Serum ermöglichen, detailliert beschrieben und hinsichtlich Spezifität, Richtigkeit und Präzision diskutiert. Vor- und Nachteile der Modifikation werden einander gegenübergestellt.

\section{Free thyroxin in serum (Equilibrium dialysis with native and diluted serum)}

Two modifications of the original STERLING-BRENNER-method for the determination of free $T_{4}$ in whole and diluted serum are described in detail. Specificity, accuracy and precision are discussed. The advantages and shortcomings of the two modifications are compared.

Zur Diagnostik von Schilddrüsenerkrankungen ist eine Vielzahl klinischer, nuklearmedizinischer und laborchemischer Verfahren erarbeitet worden, die auf Morphologie' bzw. Topik sowie Qualität und Quantität der Störung Rückschlüsse erlauben. Ziel aller Untersuchungen ist es festzustellen, ob eine Störung vorliegt, von welchem $T_{J} p$ sie ist und velches Ausmaß sie besitzt. Aus den über 30 beschriebenen und verwendeten Parametern können vier zu einem Minimalprogramm zusammengefaßt werden, das bei jeder Schilddrüsendiagnostik zu fordern ist.

1. Komplette klinische Untersuchung.

2. Radiojod-Zweiphasenfunktionsstudium.

3. Szintigramm.

4. a) Gesamtthyroxin (oder proteingebundenes Jod ${ }^{127}$ $\left.\left[\mathrm{PB}^{12} \mathrm{I}\right]^{1}\right)$ and freies Thyroxin im Serum.

b) Gesamtthyroxin (oder in zweiter Linie $\mathrm{PB}^{127} \mathrm{I}$ ) und Serum-131 J-T - Test.

Innerhalb dieses Minimalprogramms wird das Ausmaß einer Schilddrüsenfunktionsstörung vor allem durch die Bestimmung von Gesamt- und freiem Thyroxin festgelegt. Da der Wert des Gesamtthyroxins (bzw. PB ${ }^{127}$ ) durch verschiedene, nicht schilddrüsenspezifische Einflüsse (Schwangerschaft, Hepatitis, dekompensierte Leberzirrhose, Nephrose, Akromegalie, akute intermittierende Porphyrie, genetisch bedingten Mangel an Thyroxin bindendem Globulin, Östrogene, Androgene, Kortikoide, Salicylate, Phenylbutazon, Diphenylhydantoin, Dinitrophenol, Sulfonylharnstoffe u. a.). verfälscht werden kann, stellt in dieser Hinsicht die Bestimmung der Konzentration des stoffwechselaktiven freien Thyroxins oft den entscheidenden Parameter dar.

1) Abkiirzungen: $\mathrm{PB}^{127} \mathrm{I}=$ proteingebundenes Jod $^{127} ; \quad \mathrm{TBP}=$ Thyroxin bindende Proteine; TBG $=$ Thyroxin bindendes Globulin; TBPA $=$ Thyroxin bindendes Präalbumin; $\mathrm{FT}_{4}{ }^{\circ}=$ freies Thyroxin; FTBP $=$ freie Thyroxin-Bindungsstellen am Protein; $\mathrm{T}_{4}=$ Thyroxin; $\mathrm{AFT}_{4}=$ Konzentration des freien Thyroxins.
Der überwiegende Anteil des Thyroxins im Serum ist an Trägerproteine $\left(\mathrm{TBP}^{\mathbf{1}}\right)$ gebunden $\left(\mathrm{TBG}^{1}\right)$, TBPA $^{1}$ ) und Albumin). Die Wechselbeziehungen zwischen Thyroxin und Bindungsproteinen können nach dem Massenwirkungsgesetz durch folgende Gleichungen charakterisiert werden:

$$
\mathrm{FT}_{4}+\mathrm{FTBP} \rightleftharpoons \mathrm{T}_{4} \cdot \mathrm{TBP}
$$

und

$$
\frac{\left[\mathrm{FT}_{4}\right] \cdot[\mathrm{FTBP}]}{\left[\mathrm{T}_{4} \cdot \mathrm{TBP}\right]}=\mathrm{K}
$$

$\mathrm{Da}$ die Konzentration an FTBP im Sexum wesentlich höher als die des gebundenen Thyroxins ist, und die Assoziationskonstante für das Hauptbindungsprotein TBG $\left(K=10^{10}\right)$ (1) groß ist, muß die Konzentration an freiem $\mathrm{T}_{4}$ im Serum sehr klein sein.

Seit 1967 wird das freie Thyroxin von uns durch Gleichgewichtsdialyse mit nachfolgender Magnesiumchloridfällung bestimmt. Das Originalverfahren von STERLING und BrenNer (2) weist einige Nachteile auf, die wir durch eine modifizierte Methodik mit Bestimmung des freien Thyroxins aus verdünntem Serum zu umgehen versucht haben.

Im folgenden werden beide Methoden beschrieben und Vor- und Nachteile beider Modifikationen einander gegenübergestellt.

\section{Material und Methodik}

Reagenzien, Glasgeräte und apparative Ausrüstung Reagenzien

Radioaktives Thyroxin: ${ }^{125} \mathrm{~J}-\mathrm{L}-$-Thyroxin: spezifische Aktivität um $50 \mathrm{mC} / \mathrm{mg}$, angeforderte Reinheit $>95 \%$ in 50proz. Propylenglykol (Radiochemical Center, Amersham, England). Chargen von $30 \mathrm{mC} / \mathrm{mg}$ können ebenfalls verwendet werden. Nach Reinigungsdialyse (s. unten) wird die Tracer-Lösung mit Rinderserumalbumin-Lösung so verdünnt, daß eine Konzentration von etwa $0,07 \mu \mathrm{g} \mathrm{T} T_{4} / 0,1 \mathrm{ml}$ Lösung resultiert. Die so für den Test präparierte Charge wird bei $+4^{\circ}$ im Eisschrank aufbewahrt. Stabiles Thyroxin: Natrium-Pentahydrat-L-Thyroxin reinst (Serva Entwicklungslabor, Heidelberg). Di-Kalium-hydrogenphosphat, 


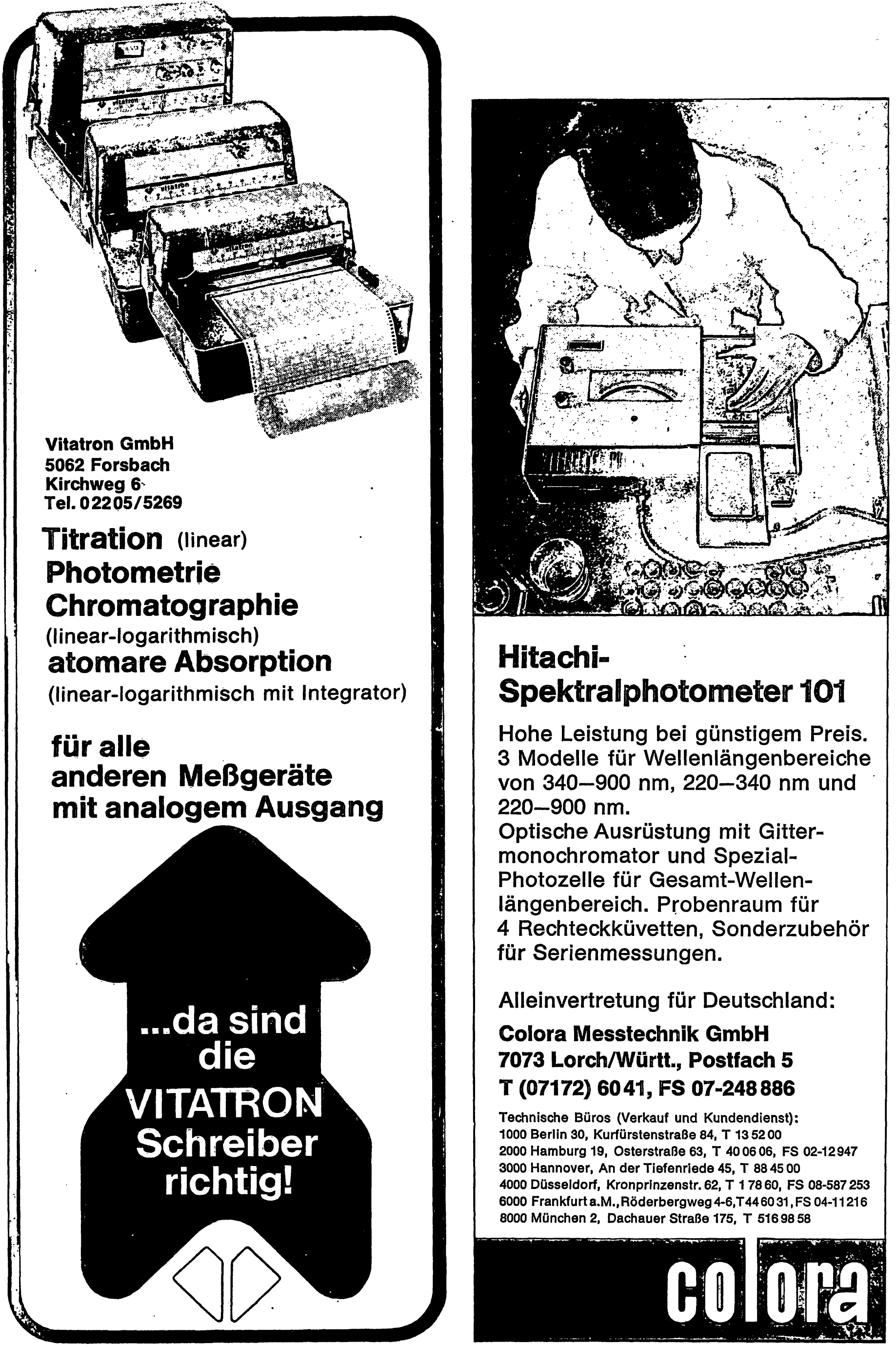




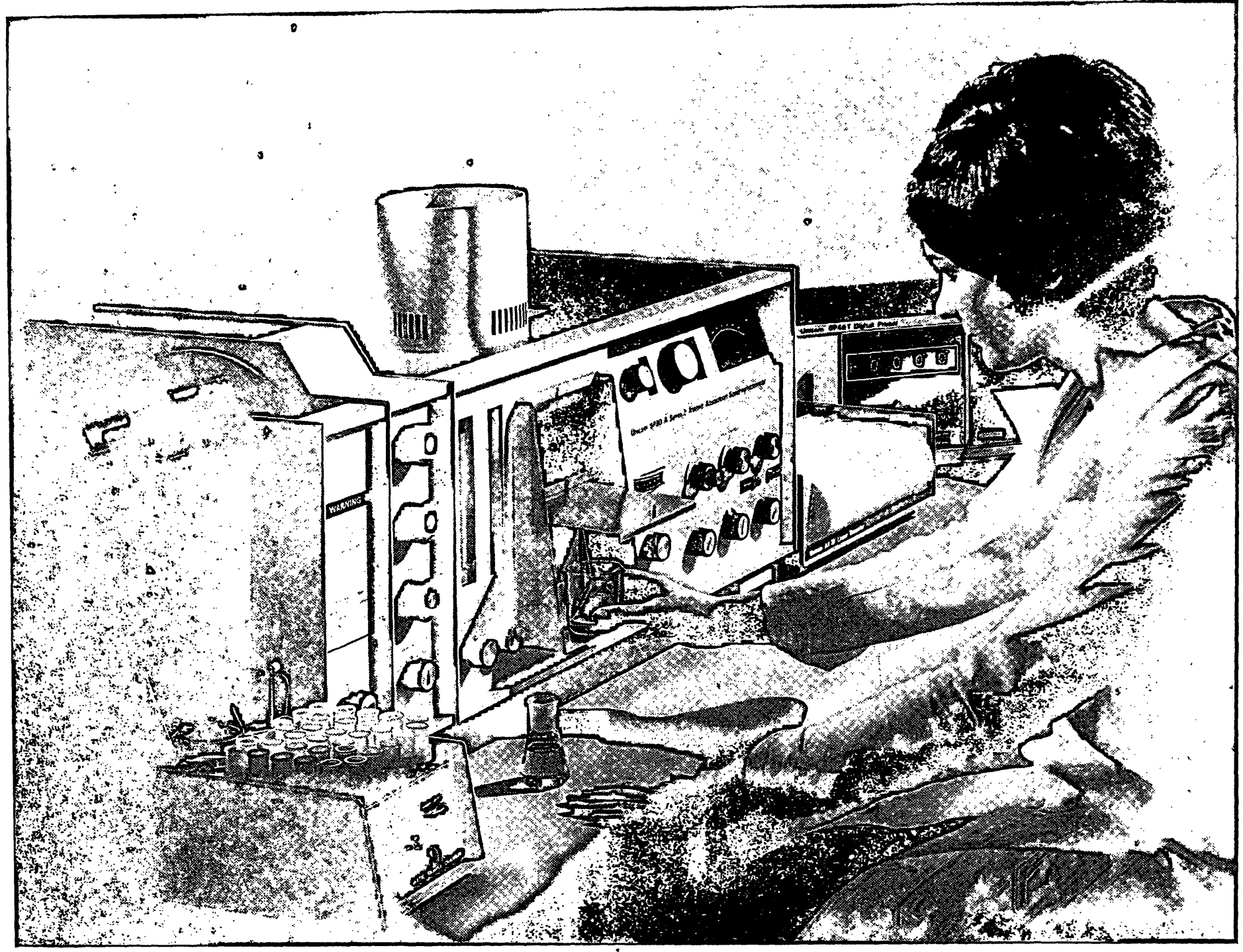

\title{
Seien Sie anspruchsvoller bei llaren Forschungs- und Routinearbeitem
}

\author{
nützen Sie die neuesten Möglichkeiten aus dem Programm PYE UNICAM
}

Das weiterentwickelte AtomabsorptionsSpektralphotometer SP 90 Serie 2 basiert auf dem Prinzip des bekannten SP 90. Es bietet Ihnen neue Vorteile durch seine lineare Extinktions-Anzeige, die kontinuierliche Skalendehnung, eine neue Lachgasbrenner-Einheit und die eingebaute Flammen-Emissions-Einheit. Zahlreiches Zubehör erweitert die Möglichkeiten: ein automatischer Probenwechsler, eine digitale Anzeige- und Drucker-Einheit, ein Lampenwechsler und ein Mehrschlitzbrenner.
Wellenlängenbereich $190 \mathrm{~nm}$ bis $770 \mathrm{~nm}$ bzw. $190 \mathrm{~nm}$ bis $852 \mathrm{~nm}$; Anschluß für Schreiber.

Anwendung: Agri-Kultur-Chemie, Biochemie, klinische Chemie, Galvanik, Nahrungsmittel, Baumaterialien, allgemeine Industrie-Chemie, Geologie, Metallurgie, Petro-Chemie, Kunststoffe, Wasser-Analysen, Textilien. Damit erschließt die Atomabsorptions-Technik der Analytik neue Möglichkeiten. In den Anwendungslaboratorien in Hamburg und Cambridge werden ständig neue Methoden ausgearbeitet.
Bitte fordern Sie ausführliches Informationsmaterial an. Es liegt für Sie bereit.

Philips Elektronik Industrie GmbH 2000 Hamburg 63 - Röntgenstraße 22 Telefon (0411) 501031

Telefon-Nummern der Büros in: Berlin (0311) 245908 . Bielefeld (0521) 23081 , Dortmund (0231) 41961 , Düsseldort (0211) 346051 , Frankfurt (0611) 79131 . Hamburg (0411) 2892-1, Hannover (0511) 16601. Kiel (0431) 7323 86, Köln (0221) 514260 , Mannheim (0621)
42016 , München (0811) 76791 , Nürnberg (0911) 464763 , Stuttgart 42016. München (0811
(0711) $589081-83$.

\section{PHILIPS Analysengeräte 开}

Wir interessieren uns für das Spektralphotometer SP 90 Serie 2 und bitten um

$\square$ Zusendung ausführliçher Unterlagen

$\square$ ein Angebot

$\square$ Besuch Ihres Beratungsingenieurs

Gewünschtes bitte ankreuzen oder ergänzen 
Kalium-dibydrogenphosphat, Di-Natrium-hydrogenphosphat, Tris, Magnesiumchlorid, Natriumchlorid, 1N Natronlauge und 32proz. Salzsäure wurden in p. a.-Qualität von der Firma Merck, Darmstadt, bezogen. Rinderserumalbumin, tein (Reinheit $>95 \%$ ) und Visking Dialysierschläuche, Typ 27/32, von der Firma ServaHeidelberg. Die Schläuche werden am Tag vor dem Versuch in Stücke von $20 \mathrm{~cm}$ Länge geschnitten, mit dest. Wasscr kurz gespült und in bidest. Wasser bei $+4^{\circ} \mathrm{im}$ Eisschrank aufbewahrt.

\section{Lösungen}

Alle Lösungen werden mit bidest. Wasser angesetzt. Folgende wrerden gebraucht:

1. Tris-NaCl-Lösung: $0,05 \mathrm{M}$ Tris zu $0,1 \mathrm{M} \mathrm{NaCl}(12,11 \mathrm{~g}$ Tris + $11,68 \mathrm{~g} \mathrm{NaCl}$ ad 21 ).

2. Isotonischer ( $310 \mathrm{mOsmol} / \mathrm{l})$ Kaliumphosphat-Puffer, $\mathrm{pH}$ :

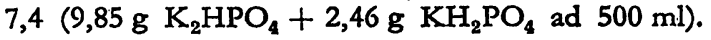

3. Magnesiumchlorid-Stammlösung $\left(\mathrm{MgCl}_{2} \cdot 6 \mathrm{H}_{2} \mathrm{O}\right) 40$ proz. (w/v).

4. a) Magnesiumchlorid-Präzipitationslösung: 10proz. $\mathrm{MgCl}_{2}$. $6 \mathrm{H}_{2} \mathrm{O}$ in Tris- $\mathrm{NaCl}, \mathrm{pH}$ 9,3: Verdünnung der 40proz. Magnesiumchlorid-Stammlösung in der Tris-NaCl-Lösung führte zu pH 9,3 ohne Titration.

4. b) Magnesiumchlorid-Waschlösung hat die gleiche Zusammensetzung wie Lösung 4a), sie wird aber mit Salzsäure auf $\mathrm{pH} 8,7$ bis 8,8 eingestellt.

5. Nicht radioaktive $T_{4}$-Lösung $\left(1^{\circ} \mathrm{mg} / \mathrm{ml}\right)$ wird vor jedem Versuch mit $0,033 \mathrm{~N} \mathrm{NaOH}$ frisch angesetzt.

6. Sörensen-Phosphat-Puffer für Reinigungsdialyse: $0,15 \mathrm{M} \mathrm{pH} \mathrm{7,4}$ $\left(20 \mathrm{~g} \mathrm{KH}_{2} \mathrm{PO}_{4}+107,34 \mathrm{~g} \mathrm{Na}_{2} \mathrm{HPO}_{4}\right.$ ad $5 \mathrm{l}$ ).

7. Rinderserumalbumin-Lösung: $0,125 \mathrm{~g} / 100 \mathrm{ml}$.

\section{Glasgeräte}

Plastik-Zentrifugeneinsätze aus Cellulose-Nitrat (Firma Beckman) Nr. 302237 (Size $\left.1^{\prime \prime} \times 3,5^{\prime \prime}\right), 25$ ml-Weithals-ErlenmeyerKolben, Zählröhrchen mit Schraubverschluß für PhilipsBohtloch-Zählgerät, geeichte 3- und 2-ml-Vollpipetten, Reagenz und Zentrifugenröhrchen aus Polystyrol $(16 \times 95 \mathrm{~mm})$, Firma Sarstedt, 5523 Nümbrecht. Alle Glasgeräte müssen bei mehrfachem Gebrauch sorgfältig gereinigt werden: Vorspülen mit Wasser, 24 stdg. Einlegen in Extran-Lösung (Firma Merck, Darmstadt), Spülen mit Wasser, Einlegen für 12-24 Stdn. in bidest. Wasser, Trocknen an der Luft.

\section{Apparative Ausrïstung}

Thermokonstanter Wasserbadschüttler, Firma Bühler, Tübingen, Typ th 15 (Kapazität: 28 Erlenmeyer-Kölbchen bzw. 36 PlastikTubes), 2 halbautomatische Pipetten: Autopetten mit $10 \mathrm{ml}$ Inhalt (Firma Gemetron, Hannover), 1 Repette $(2 \mathrm{ml})$ zum Pipettieren des Tracers (Firma Jencons, Hemel Hempstead, England), Eppendorf-Mikroliter-Pipette $0,5 \mathrm{ml}$. Automatischer Mixer: Super-Mixer (Lab. Line Instruments, Melrose Park, Ill., USA, Firma Jürgens, Hannover), 1 Stock-Zentrifuge mit 8 Bechern à 8 Röhrchen (Firma Stock, Marburg), Wasserstrahlpumpe, Zählgerät (Firma Philips, 2 Kanal-Bohrlochgerät), 1 Rührgerät (Laborrührer Typ RZR, Firma Heidolph L. G., Kelheim).

\section{Reinigungsdialyse}

Die gelieferten Tracerchargen enthalten nach eigenen Untersuchungen (3) nur etwa $70-80 \%{ }^{125} \mathrm{~J}-\mathrm{T}_{4}$, wobei der $\mathrm{Grad}$ und die Art der radioaktiven Verunreinigungen von Charge zu Charge stark schwanken. $\mathrm{Da}$ ein Teil dieser Kontaminationen ebenfalls mit Magnesiumchlorid fällbar und gut dialysierbar ist (3), können die errechneten freien $\mathrm{T}_{4}$-Werte fälschlich zu hoch liegen. Eine Vorreinigung des Tracers ist deshalb erforderlich. Gereinigte Chargen enthalten $\mathrm{zwischen} 85$ und $95 \%{ }^{125} \mathrm{~J}-\mathrm{T}_{4}$. - Die Reinigungsdialyse geschieht nach der Vorschrift von SchussLeR und Plager (4). - Das zu reinigende Tracervolumen wird mit der gleichen Menge an Serum gemischt und gegen 7,51 des $0,15 \mathrm{M}$ Sörensen-Phosphat-Puffers bei pH 7,4, Dunkelheit und $+4^{\circ}$ über
24 Stdn. unter konstantem Rühren dialysiert. Der Inhalt des Dialysiersäckchens wird anschließend mit Rinderserumalbumin so verdünnt, daß eine Konzentration von etwa $0,07 \mu \mathrm{g} \mathrm{T}_{4}$ pro $0,1 \mathrm{ml}$ Lösung resultiert.

Prinzip der Methode

Das Verfahren beruht auf der von SterLing und Brenner (2) eingeführten Gleichgewichtsdialyse mit nachfolgender Magnesiumchlorid-Präzipitation des Dialysat- $T_{4}$ (vgl. auch HerrmanN, KrüSKemper, Müller (3)). Für die Richtigkeit des Prinzips wird vorausgesetzt, $\mathrm{da} \beta$ radioaktives Tracer-Thyroxin denselben Gesetzmäßigkeiten gehorcht wie endogenes Serum-Thyroxin: Nach Zugabe einer Tracermenge an radioaktivem Thyroxin zum Serum wird der freie Anteil des $\mathrm{T}_{4}$ vom gebundenen durch Dialyse und von radioaktiven Kontaminationen des Tracers durch Magnesiumchlorid-Fällung getrennt.

\section{Durchführung der Bestimmung} Aus unverdinntem Serum

1. Trennung von gebundenem und freiem $T_{4}$ :

$\mathrm{Zu} 3 \mathrm{ml}$ Serum in einem Polystyrol-Röhrchen werden 0,075 bis $0,1 \mathrm{ml}$ des vorgereinigten Tracers pipettiert (bei Serienbestimmung Repette benutzen) und mit dem Supermixer gut gemischt. $0,5 \mathrm{ml}$ des radioaktiven Serums (bei Serumbestimmungen $0,5 \mathrm{ml}$ Eppendorf-Pipette benutzen) werden in ein Philips-Zählröhrchen überführt (Vollwert).

Die 25 ml-Erlenmeyerkölbchen werden kurz mit KaliumphosphatPuffer ausgespült und anschließend mit $9 \mathrm{ml}$ des gleichen Kaliumphosphat-Dialysierpuffers beschickt (bei Serienbestimmungen: $10 \mathrm{ml}$ Autopipette benutzen). Die vorbereiteten Dialysierschläuche werden durch Ausschütteln mit der Hand vom Wasser befreit (intensiveres Trocknen unnötig), in U-Form gebogen und in die Erlenmeyer-Kolben getaucht, so daß die beiden Enden aus der Öfnung des Kolbens herausragen. Durch Einblasen werden die beiden Schenkel des U geöffnet. $2 \mathrm{ml}$ des präparierten Serums werden in einen der Schenkel pipettiert, und der ErlenmeyerKolben mit einem Gummistopfen verschlossen. Anschließend Inkubation der Proben bei $37^{\circ}$ im Wasserbad unter Schütteln mit einer Frequenz von 100-120 Schlägen/Min. über $16 \mathrm{Stdn}$.

2. Trennung des Dialysat- $T_{4}$ von radioaktiven Kontaminationen. $\mathrm{Nach}$ der $16 \mathrm{stdg}$. Inkubation werden je $3 \mathrm{ml}$ Dialysat in ein Zählröhrchen pipettiert, $2 \mathrm{ml}$ der "kalten" Carrier-T T-Lösung $^{-}$ $(1 \mathrm{mg} / \mathrm{ml})$ und $0,2 \mathrm{ml} 1 \mathrm{~N} \mathrm{NaOH}$ zugesetzt, das Röhrchen auf dem Supermixer geschüttelt und danach $1 \mathrm{ml}$ der Magnesium-ChloridPräzipitationslösung zugegeben. Nach nochmaligem Mixen wird das weiße Präzipitat abzentrifugiert (ungefähr 1 Min. bei 2000 U/ Min., nicht längerl) und der Überstand mit der Wasserstrahlpumpe abgesaugt. Das Präzipitat wird noch $2 \mathrm{mal} \mathrm{mit} \mathrm{je} 5 \mathrm{ml}$ der Magnesiumchlorid-Waschlösung gewaschen (Supermixer benutzen) und dann im Philips-Bohrlochgerät gezählt.

\section{Aus 1:21,25 verdünntem Serum}

Die U-Form des Dialysierschlauches und die Inkubation im Erlenmeyer-Kolben eignen sich nicht für Bestimmungen aus verdünntem Serum. Der Dialysierschlauch wird statt dessen an einem Ende durch mehrfaches Knoten (Nähgarn) verschlossen und in einem mit $9 \mathrm{ml}$ Puffer beschickten Plastikröhrchen inkubiert.

$0,20 \mathrm{ml}$ Serum (Eppendorf-Pipettc) werden mit 4,0 ml Kaliumphosphat-Puffer in einem Zählröhrchen (Zipette) verdünnt und mit $0,05 \mathrm{ml}$ Tracer versetzt. Der vorgereinigte Tracer (Konzentration ungefähr $0,07 \mu \mathrm{g} \mathrm{T} / 4,1 \mathrm{ml}$ ) wurde vorher $1: 7$ mit Kaliumphosphat-Puffer verdünnt. Nach gutem Mischen werden $3 \mathrm{ml}$ der radioaktiven Serumverdünnung in den vorbereiteten Dialysierschlauch pipettiert; dic Radioaktivität der restlichen $1,25 \mathrm{ml}$ dient als Vollwert. Die Inkubationszeit und die Aufarbeitung des Dialysats ist für beide Verfahren identisch.

Berechnung der Werte

Fiir unverdinutes Serum

Der Prozentsatz des freien Thyroxins wird dargestellt durch den Quotienten aus der Radioaktivität des Präzipitats und der Radio- 
aktivität im Original-Serum. Da die Radioaktivität des Präzipitats den freien $T_{4}$-Gchalt in $3 \mathrm{ml}$ Dialysat repräsentiert, wird es mit der Radioaktivität von $3 \mathrm{ml}$ Serum verglichen. $\mathrm{Da}$ das Gleichgewicht zwischen freiem und gebundenem $T_{4}$ im Serum fast vollständig auf der Seite des gebundenen Anteils liegt, sind innerhalb eines gewissen Bereiches die Volumina an eingesetztem Serum und Dialysierpuffer ohne wesentlichen Einfluß. Entscheidende Parameter für die Berechnung sind genaues Pipettieren der $3 \mathrm{ml}$ des Dialysates und des $0,5 \mathrm{ml}$ Vollwertes.

$$
\mathrm{FT}_{4}(\%)=\frac{(\mathrm{Imp} \cdot / \text { Min. Präzipitat }- \text { Imp./Min. Leerwert }}{\text { der Zählröhrchen) } \cdot 100}
$$

Fiir 1:21,25 verdiinntes Serum

In einer experimentellen und mathematischen Analyse haben OpPenhermer und Mitarbeiter (5) nachgewiesen, daß der Prozentwert des freien $\mathrm{T}_{4}$ entsprechend dem Grad der Serumverdünnung zunimmt; daher

$$
\mathrm{FT}_{4}(\%)=\frac{(\text { Imp./Min. Präzipitat }- \text { Imp./Min. Leerwẹt }}{\text { der Röhrchen) } \cdot 100}
$$

Zur Berechnung der Konzentration an freiem $\mathrm{T}_{4}$ ist die Bestimmung des Gesamt-Thyroxins im Serum entweder nach einer direkten Methode oder durch Errechnung aus dem PB ${ }^{127}$ I durch Multiplikation mit dem Faktor.1,53 erforderlich:

$$
\mathrm{AFT}_{4}(\mathrm{ng} / 100 \mathrm{ml})=\frac{\% \mathrm{FT}_{4} \cdot \mathrm{Gesamt}_{-} \mathrm{T}_{4}(\mu \mathrm{g} / 100 \mathrm{ml}) \cdot 1000}{100}
$$

\section{Ergebnisse und Diskussion}

Tabelle 1 enthält Angaben über die von uns gefundenen Werte bei Eu-, Hyper- und Hypothyreose. Die Spezifität der Methode hängt ganz von der Reinheit des Tracers ab. Schussier und Plager (4) konnten nachweisen, daß die Diskrepanzen zwischen Bestimmungen aus unverdünntem und verdünntem Serum auf radioaktiven Kontaminationen der kommerziellen Tracer-
Chargen beruhen. Die Anwesenheit von Verunreinigungen, vor allem mit verschiedenen anderen radioaktiven Thyroninen in wechselndem Ausmaß und deren Fällbarkeit mit Magnesium-Chlorid, haben wir früher zeigen können (3). Nach Vorreinigung des Tracers durch Dialyse haben wir zwischen Bestimmungen aus unverdünntem und verdünntem Serum keine Unterschiede gefunden. Wegen der stark wechselnden Reinheit der Tracer-Chargen ist eine routinemäßige Reinigungsdialyse unbedingt erforderlich.

Die Richtigkeit der Methode wird vor allem durch Zusätze zu den Pufferlösungen beeinflußt, die durch Kompetition um die Bindungsstellen am Protein das Gleichgewicht $z$ wischen gebundenem und freiem $T_{4}$ verfälschen. Das von uns früher als Bakteriostatikum im Dialysierpuffer verwandte Merthiolate (Cialit) erwies sich noch in geringer Konzentration als Kompetitor. Allgemein sollte besonders bei Anwendung der Verdünnungsmethode jeglicher Zusatz zum Dialysierpuffer vermieden werden. Dagegen hat ein Tetracyclinzusatz von $1,5 \mathrm{mg} / 100 \mathrm{ml}$ zum Puffer bei Bestimmungen aus unverdünntem Serum keinen Einfluß auf die Ergebnisse.

Daten für die Präzision der beiden Methoden sind aus Tabelle $2 \mathrm{zu}$ entnehmen, aufgeführt sind Mittelwerte, die Streuung und der Variationskoeffizient (V. K.). Die Werte entsprechen Bestimmungen aus dem gleichen Serum mit beiden Methoden.

Das STTERLING-Brenner-Verfahren zur Bestimmung des freien $T_{4}$ hat wegen der relativen Unkompliziertheit der technischen Durchführung weiteste Anwendung gefunden. Die hier beschriebenen zwei Modifikationen

\begin{tabular}{|c|c|c|c|c|}
\hline & Euthyreose & Hyperthyreose & Hypothyreose & \\
\hline $\mathrm{PB}^{121} \mathrm{l}(\mu \mathrm{g} / 100 \mathrm{ml})$ & $\begin{array}{c}5,6 \underset{ }{ \pm 3,6}-1,2(95) \\
=7,9]\end{array}$ & $\begin{array}{c}14,4 \pm 6,5(56) \\
{[7,8-26,6]}\end{array}$ & $\begin{array}{c}1,4 \pm 0,8(18) \\
{[0,2-2,9]}\end{array}$ & . \\
\hline Gesamt-T $_{4}(\mu \mathrm{g} / 100 \mathrm{ml})$ & $\begin{array}{c}8,4 \pm 1,8(61) \\
{[5,5-11,5]}\end{array}$ & $\begin{array}{c}20,3 \\
{[11,3-36,7(21)}\end{array}$ & $\begin{array}{c}1,9 \pm 1,0(12) \\
{[0,3-4,0]}\end{array}$ & \\
\hline $\mathrm{FT}_{4}(\%)$ & $\begin{array}{c}0,025 \pm 0,005(118) \\
{[0,018-0,036]}\end{array}$ & $\begin{array}{c}0,055 \pm 0,019(56) \\
{[0,024-0,086]}\end{array}$ & $\begin{array}{c}0,018 \pm 0,005(18) \\
{[0,014-0,029]}\end{array}$ & \\
\hline $\mathrm{AFT}_{4}(\mathrm{ng} / 100 \mathrm{ml})$ & $\begin{array}{c}2,1 \\
{[1,3-3,5]}\end{array}$ & $\begin{array}{c}12,6 \pm 8,7(56) \\
{[4,1-28,9]}\end{array}$ & $\begin{array}{c}0,39 \pm 0,31(18) \\
{[0,1-1,3]}\end{array}$ & \\
\hline
\end{tabular}
der Originalmethode weisen bei etwa gleicher Präzi-

Tab. 1

Mittelwerte, Streuung (s), Bereiche und Fallzahl für das $P B^{127}{ }^{12}$, Gesamt- $T_{4}$, prozentuale freie $T_{4}$ und die Konzentration des freien Thyroxins im Serum bei Eu-, Hyper- und Hypothyreose

\begin{tabular}{|c|c|c|c|c|c|c|c|}
\hline & & \multicolumn{3}{|c|}{ unverd. Serum } & \multicolumn{3}{|c|}{$1: 21,25$ verd. Serum } \\
\hline & & $\begin{array}{l}\mathrm{FT},[\%] \\
(\bar{x} \pm s)\end{array}$ & n & VK $[\%]$ & $\begin{array}{l}F T_{4}[\%] \\
(\bar{x} \pm s)\end{array}$ & $\mathbf{n}$ & VK $[\%]$ \\
\hline & Präzision in Serie & $0,030 \pm 0,002$ & 14 & 7,0 & $0,031 \pm 0,0017$ & 10 & 5,5 \\
\hline & $\begin{array}{l}\text { Präzision von Tag zu Tag } \\
\text { Präzision in verschiedenen } \\
\text { Bereichen }\end{array}$ & $0,029 \pm 0,0018$ & 10 & 6,3 & $0,031 \pm 0,003$ & 6 & 9,7 \\
\hline & $\begin{array}{l}\text { Hypothyreose } \\
\text { Euthyreose I }\end{array}$ & $\begin{array}{l}0,015 \pm 0,0008 \\
0,027 \pm 0,0015\end{array}$ & $\begin{array}{r}4 \\
18\end{array}$ & $\begin{array}{l}5,3 \\
5,5\end{array}$ & $0,016 \pm 0,0022$ & 5 & 13,7 \\
\hline & Euthyreose II & $0,030 \pm 0,002$ & 10 & 7,0 & $0,031 \pm 0,0024$ & 5 & 7,7 \\
\hline & Hyperthyreose I & $0,041 \pm 0,003^{\circ}$ & 7 & 7,3 & $0,042 \pm 0,0022$ & 5 & 5,2 \\
\hline$\cdot$ & Hyperthyreose II & $0,057 \pm 0,0047$ & 5 & 8,2 & & & \\
\hline
\end{tabular}

Tab. 2

Vergleich der Präzisionsmessung ,,in Serie“, „von Tag zu Tag“ und in verschiedenen Bereichen des freien $T_{4}$ zwischen Bestimmungen aus unverdünntem und verdünntem Serum 
Tab. 3

Gegenüberstellung von Vor- und Nachteilen der Bestimmung aus nativem und verdünntem Serum

Bestimmung aus unverd. Serum

a) kein Verknoten der Schläuche b) wenig störanfällig

$\begin{array}{ll}\text { Vorteile } & \text { a) kein Verknoten der Schläuche } \\ \text { b) wenig störanfällig }\end{array}$

Bestimmung aus $1: 21,25$ verd. Serum
a) Einzelbestimmung aus nur $0,20 \mathrm{ml}$ Serum möglich
b) finanziell wenig aufwendig, da wenig Tracer benötigt
c) Kapazität - 72 Proben
a) zeitaufwendiges Verknoten der Schläuche
b) relativ störanfällig

sion der Ergebnisse einige Vor- und Nachteile auf, die in Tabelle 3 aufgeführt sind.

Trotz mehrfacher Versuche ist es uns nicht gelungen, die Vorteile beider Modifikationen zu kombinieren: Werte aus Bestimmungen mit nur $1 \mathrm{ml}$ unverdünntem Serum liegen wenig, aber signifikant unter den mit 2 oder $3 \mathrm{ml}$ Serum ermittelten. Aus ungeklärten Gründen steigt die Streuung von Mehrfachbestimmungen erheblich an, wenn verdünntes Serum in U-förmigen Schläuchen in Erlenmeyer-Kolben dialysiert wird. Trotz der Notwendigkeit, die Dialysierschläuche mit Garn verknoten zu müssen (andere Verschlußverfahren haben sich bei uns nicht bewährt), wenden wir z. Z. die Bestimmung aus verdünntem Serum an. Die Möglichkeit, aus kleinen Serummengen Doppel- und Dreifachwerte bestimmen und eine Bestimmung gegebenenfalls wiederholen zu können, sowie der bei weitem geringere finanzielle Aufwand überwiegen den Nachteil der größeren Störanfälligkeit und des größeren Zeitaufwandes.

Abgesehen von der 16 stdg. Inkubationszeit beträgt die reine Arbeitszeit für eine Person zum Bestimmen von etwa 80 Proben in dem von uns entwickelten Ablauf etwa 4 bis $5 \mathrm{Stdn}$. Zu dieser Spanne müssen für das
Knoten von 80 Schläuchen noch etwa $11 / 2$ bis 2 Stdn. hinzugerechnet werden. Die Handhabung der Dialysierschläuche erfordert große Sorgfalt. Auf mehrfaches Spülen der Membranen und langes Einlegen in verdünnte $\mathrm{HNO}_{3}$ (STERLING) kann völlig verzichtet werden, zumal intensive Manipulationen an den empfindlichen Schläuchen nur die Gefahr von Undichtigkeiten erhöht.

Bei Benutzung von unverdünntem Serum und Puffer ohne Bakteriostatikum ist das Dialysat nach 16 stdg. Inkubation gewöhnlich infolge bakteriellen Wachstums trübe. Durch Zusatz von $1,5 \mathrm{mg} / 100 \mathrm{ml}$ Tetracyclin zum Puffer lassen sich klare Dialysate erzielen, die Ergebnisse werden dadurch nicht verändert.

Bei Verwendung von vorgereinigtem Tracer kann auf einen dritten Waschvorgang (STERLING) verzichtet werden. Vorgereinigte, gealterte Tracer-Chargen können ohne weiteres ein zweites Mal mit der Dialyse von Zerfallsprodukten gereinigt werden. Zunehmende radioaktive Tracerkontaminationen machen sich besonders bei unverdünntem Serum in einem Ansteigen der Pool-Serum-Kontrollwerte, die bei jedem Versuch mitbestimmt werden sollten, bemerkbar.

\section{Literatur}

1. Robrins, J. und J. E. Rall, Recent Progr. Hormone Res., New York 13, 161 (1957). - 2. SterLING, K. und M. A. Brenner, J. Clin. Invest. 45, 155 (1966). - 3. Herramann, J., H. L. Krüskemper und H. Müller, Clin. Chim. Acta. Amsterdam
24, 457 (1969). - 4. Schussler, G. C. und J. E. Plager, J. Clin. Endocr., Springfield 27, 242 (1967). - 5. Oppenheimer, J. H. und M. J. Surks, J. Clin. Endocr., Springfield 24, 195 (1966).

Dr. J. Herrmann

Prof. Dr. H. L. Krüskemper Med. Hochschule Hannover Department Innere Medizin Abt. f. Klin. Endokrin.

3 Hannover

Podbielskistr. 380 